\title{
$\therefore$ Recent Research on Effect of COVID-19 on Diabetic Patients
}

\author{
IJCRR \\ Section: Healthcare \\ ISI Impact Factor \\ (2019-20): 1.628 \\ IC Value (2019): 90.81 \\ $\operatorname{SJIF}(2020)=7.893$ \\ Copyright@IJCRR
}

\section{Mudita, Ramneet, Gupta K., Gupta D.*}

Chitkara University lnstitute of Engineering and Technology, Chitkara University, Punjab, India.

\section{ABSTRACT}

Introduction: The current outbreak of the novel coronavirus disease 2019 (COVID-19) has left the whole world traumatized. It is prefixed with the word "novel" because it comes under the new strain of the virus that has not been reported before. This virus outbreak has disrupted human life in the most petrifying way worldwide. Numerous researchers have contributed since the beginning of this pandemic.

Objective: The present study aims to analyze the work done in this field through a bibliometric review to investigate the association between COVID-19 and diabetes.

Methods: We explored the Scopus database for publications and the time frame selected for review is the beginning of this pandemic to April 25, 2021. The inclusion criteria were met only by 60 papers and they came from 15 different countries.

Results: The United States gave the highest number of publications with a count of 16 (26\%) and followed by India with 8 publications (13\%). This paper gives some major insights regarding the flow of current research using Biblioshiny.

Conclusion: This study aims to explore the recent trends in fast-growing publications to present a bibliometric analysis of publications on diabetic people having coronavirus since its outbreak in December 2019.

Key Words: Bibliometric, COVID-19, Diabetes, Pandemic, Risk Factor

\section{INTRODUCTION}

Coronaviruses are positive-sense single-stranded RNA viruses broadly spread worldwide. The groups of pneumonia cases of undetermined aetiology emerged in the Hubei Province of Wuhan in China in December 2019. ${ }^{1}$ An extensive sequencing examination of lower respiratory tract specimens revealed the coronavirus as a causative agent, which was called Severe Acute Respiratory Syndrome-Coronavirus-2 (SARS-CoV-2) that gave rise to a disease called COVID-19. ${ }^{2,3}$

COVID-19 is the most recently discovered disease that has affected more than one crore person worldwide. It has emerged as a quickly growing communicable disease which has been announced as a pandemic disease by the World Health Organization (WHO).

On 30 January 2020, WHO declared the outbreak of COVID-19 as a Public Health Emergency of International Concern, and this epidemic was promoted to pandemic on 11
March 2020. As of today (25.04.2021) in more than 200 countries, 146,054,107 confirmed cases are recorded with 3,092,410 deaths as shown in Fig. . $^{4}$

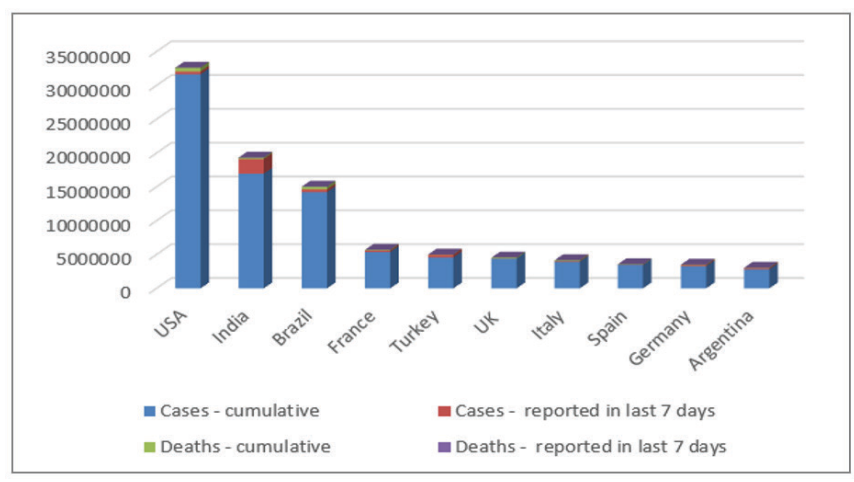

Figure 1: Country-wise data of Covid'19 victims.

Due to COVID-19, several nations have applied a lockdown system for the betterment of their people. Thus, this practice

Corresponding Author:

Gupta D., Chitkara University Institute of Engineering and Technology, Chitkara University, Punjab, India. Ph:+91-7015914724; Email: deepali.gupta@chitkara.edu.in

ISSN: 2231-2196 (Print) ISSN: 0975-5241 (Online)

Received: 24.03 .2021

Revised: 12.04 .2021

Accepted: 05.05 .2021

Published: 11.06 .2021 
adversely affects human life socially, economically and emotionally.

Diabetes is one of the main sources of mortality and morbidity on the planet and is mainly connected with significant cardiovascular and renal complications. The strength of the connection between the two pandemics, namely, COVID-19 and diabetes has been investigated in observational cohorts around the world. Diabetic patients have a high chance of risk of serious complications such as Adult Respiratory Distress Syndrome or failure of multi-organs. So, a bibliometric review is conducted to provide a summary of COVID-19 and diabetes. We believe that this analysis can contribute to future research by providing meaningful information and helps for better management of diabetic patients in COVID-19.

The evidence of epidemiologic recommends that an increased risk of communicable diseases is linked with diabetes. Also, diabetic patients are at high risk of pneumococcal bacteremia diseases and nosocomial bacteremia with a death rate as high as $50 \%{ }^{8}$ This ailment is correlated with several microvascular and macrovascular complications that affect the survival of patients. ${ }^{9}$ The pervasiveness of diabetes in humans affected by the virus is equal or slightly lower as compared to the general population as per various studies. ${ }^{10,11}$ A research in Wuhan exposed that out of the 41 COVID-19 cases, 32\% had underlying disorders, and amongst them, $20 \%$ had diabetes. ${ }^{12}$ Therefore, diabetic patients are at high risk of hospitalization and mortality for the COVID-19 virus. So, patients having diabetes need to pay more attention if there is an occurrence of fast deterioration. Patients with diabetes should deal effectively with the difficulty of its treatment and management. This bibliometric analysis represents the most prominent references linked with diabetes and COVID-19 and helps in enhancing the understanding of research in the context of diabetic COVID-19 patients.

\section{MATERIALS AND METHODS}

All publications were extracted from the Scopus database which had been studied for this paper because Scopus is considered as the most extensive peer-reviewed journal database among others present in the world that fits best for scientific academic data. ${ }^{13}$ The search keywords were applied as follows: TITLE-ABS-KEY ("COVID-19") AND TITLE-ABS-KEY ("Diabetes"). The literature search was filtered to incorporate papers published till 10 June 2020. The following keywords "'pandemic", "COVID-19", "risk factor" and "diabetes" were used with interposition of "AND" Boolean operator. The following information was used: document title, year, author, source, keywords, citations, document and source type and affiliations. The software R-Studio is used to carry out statistical analysis. In this study, we applied computable methods for statistical analysis, including the Biblioshiny $\mathrm{R}$ package. ${ }^{14}$ We also used the scientific literature available on the US Centers for Disease Control and Prevention and WHO websites.

\section{RESULTS}

In total, 60 documents met the selection criteria. Publications came from many countries worldwide. In terms of document count, the United States $(26 \%)$ is top in this list followed by India (13\%), China (10\%), Italy (10\%), Brazil (8\%) and others as shown in Fig. 2.

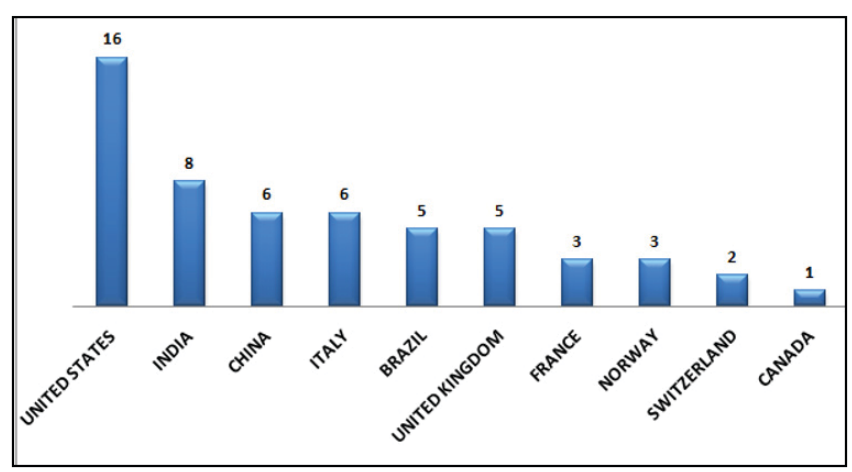

Figure 2: Top Ten Countries.

The seven most frequently used author keywords as shown in Fig. 3 are COVID-19 with 33 occurrences, diabetes with 30 , telemedicine with 9 , sars-cov- 2 with 7 , coronavirus with 7 , pandemic with 5 and risk with 4 occurrences.

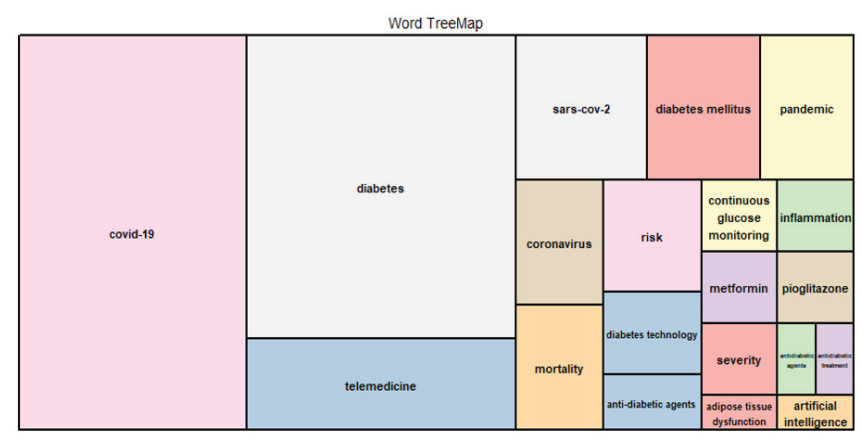

Figure 3: Top Twenty Keywords.

According to 60 documents, the top 10 cited sources are shown in Fig. 4. LANCET is at the top of this list followed by Diabetes Care and NEJM. 


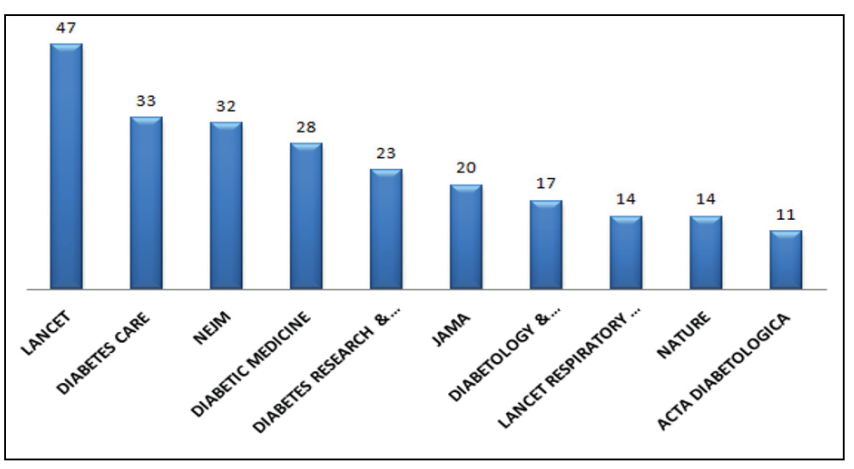

Figure 4: Top Ten Cited Sources.

The documents that met our selection criteria were distinguished across nine document types. These 9 types of documents were article $(35 \%)$, note $(30 \%)$, letter $(18 \%)$, review $(8.3 \%)$, editorial $(6.7 \%)$ and conference paper $(1.7 \%)$ as shown in Fig. 5.

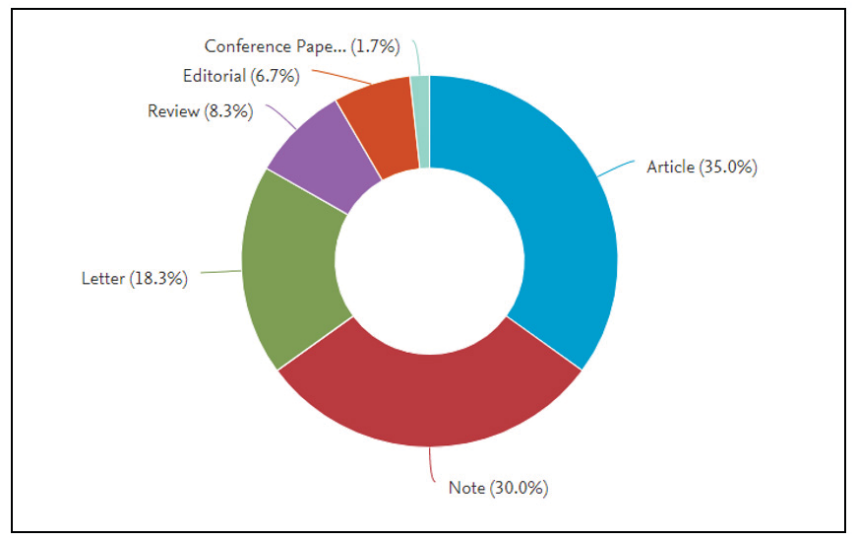

Figure 5: Document Type Distribution.

Fig. 6 summarizes the results matching the most relevant countries, their authors and affiliations. Y. Zhang has published maximum of papers from Shanghai Jiao Tong University School of Medicine of China followed by A.K. Singh, A. Hussain and R. Singh also published a good amount of papers from GD Hospital \& Diabetes Institute, India.

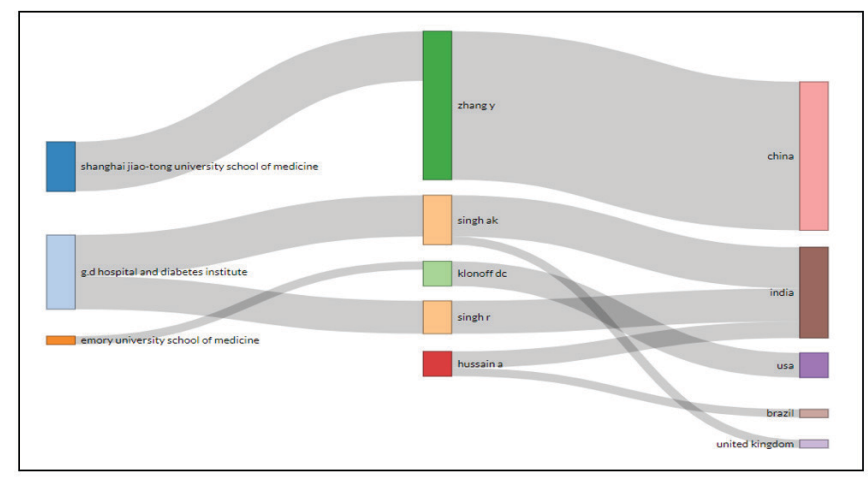

Figure 6: Summary plot of the most productive countries on the right, authors in the middle and the affiliations on the left.

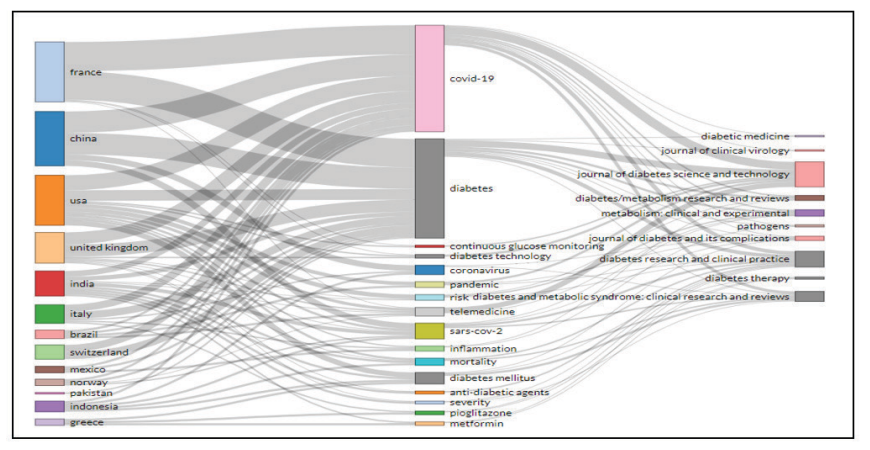

Figure 7: Summary of the most contributing countries on left, keywords in middle and sources on right.

The outcomes matching the most contributing countries, keywords and sources are summarized in Fig. 7. The most frequently used keyword is "COVID-19" by France and then followed by China, USA, UK, Switzerland, Italy and India and the Journal of Diabetes Science and Technology has maximum occurrences of this keyword followed by Diabetes and Metabolic Syndrome: Clinical Research and Reviews. The second most common keyword is "diabetes" used by China and then followed by France, the USA, the UK, India, Italy and Brazil and the Journal of Diabetes Science and Technology has the maximum occurrences of this keyword followed by Diabetes Research and Clinical Practice.

\section{DISCUSSION}

The progression of the immediate influence of the COVID-19 pandemic on diabetic patients is reviewed and interpreted by this bibliometric analysis. The included papers only cover the literature of COVID-19 \& Diabetes and the focus of these research papers exhibited an outstanding rise in the number of papers. A huge inter-collaboration and intra-collaboration network between profoundly productive authors and organizations were found. This paper leads to intrinsic bias because we used only the Scopus database and results can vary according to other databases or on the inclusion of other search terms. Our bibliometric analysis gives a detailed quantitative review as well as confirms the feasibility of implementation and scale-up of networks.

\section{CONCLUSION}

The outbreak of COVID-19 has made a significant impact on human lives and increased the concern for public well-being. COVID -19 had been spreading rapidly and affecting a large number of people, so, it inspired researchers to research in this field. This paper aims to analyze 60 publications related to COVID -19 and diabetes using a bibliometric review. The subject areas with titles, keywords, and abstract criteria were utilized as a source for obtaining search results using Biblioshiny. 
Among all countries, the United States contributed the most in terms of publications followed by India. COVID-19, diabetes and telemedicine became the most widely used keywords. LANCET is at the top of the list of cited sources followed by Diabetes Care and NEJM. 35\% of the total documents are of article type and the authors from China and India published the maximum number of papers. Journal of Diabetes Science and Technology has maximum occurrences of the most widely used keywords. So, we can conclude that this analysis can be beneficial as it provides a global bibliometric evaluation of two pandemics, COVID-19 and Diabetes which may facilitate ongoing and future research.

\section{ACKNOWLEDGEMENT}

The authors acknowledge the immense help received from the scholars whose articles are cited and included in references of this manuscript. The authors are also grateful to authors/editors/publishers of all those articles, journals and books from where the literature for this article has been reviewed and discussed.

Conflict of Interest: The authors declare that they have no conflict of interest.

Financial Support: This Research project did not receive any grants from any specific funding agency or third party.

Ethical Approval: The contents of this manuscript do not involve any research involving human participants or animals performed by any of the authors.

\section{Author Contribution}

All authors have contributed to the design, implementation, analysis and discussion of the results and also contributed to the writing of the manuscript. All authors have read and approved the final manuscript.

\section{REFERENCES}

1. Rothan HA, Byrareddy SN. The epidemiology and pathogenesis of coronavirus disease (COVID-19) outbreak. J. Autoimmun. 2020:102433.

2. Yang X, Yu Y, Xu J, Shu H, Liu H, et al. Clinical course and outcomes of critically ill patients with SARS-CoV-2 pneumonia in Wuhan, China: a single-centre, retrospective, observational study. Lancet Respir Med. 2020;24(7): 701-708.
3. World Health Organization [Internet]. Naming the coronavirus disease (COVID-19) and the virus that causes it. 2020. Available from: https://www.who.int/emergencies/diseases/novelcoronavirus-2019/technical-guidance/naming-the-coronavirusdisease-(covid-2019)-and-the-virus-that-causes-it (Accessed 12 June 2020).

4. World Health Organization [Internet]. Coronavirus disease (COVID-19) Pandemic. 2020. Available from: https://www. who.int/emergencies/diseases/novel-coronavirus-2019 (Accessed 12 June 2020).

5. Koon OE. The impact of socio-cultural influences on the COVID-19 measures-reflections from Singapore. J. Pain Symptom Manag. 2020.

6. Nicola M, Alsafi Z, Sohrabi C, Kerwan A, Al-Jabir A, Iosifidis C, Agha M, Agha R. The socio-economic implications of the coronavirus and COVID-19 pandemic: a review. Int J Surg. 2020;6(2):671-675.

7. Kang L, Ma S, Chen M, Yang J, Wang YS. Impact on mental health and perceptions of psychological care among medical and nursing staff in Wuhan during the 2019 novel coronavirus disease outbreak: A cross-sectional study. Brain Behav Immun. 2020; 7(3):80-77.

8. American Diabetes Association [Internet]. 4. Comprehensive Medical Evaluation and Assessment of Comorbidities: Standards of Medical Care in Diabetes-2020. Diabetes Care. 2020; 43(Suppl 1): S37. Available from: https://care.diabetesjournals. org/content/43/Supplement_1/S37 (Accessed 12 June 2020).

9. Williams R, Karuranga S, Malanda B, Saeedi P, Basit A, Besançon S, Bommer C, Esteghamati A, Ogurtsova K, Zhang P, Colagiuri S. Global and regional estimates and projections of diabetes-related health expenditure: Results from the International Diabetes Federation Diabetes Atlas. Diabetes Res Clin Pract. 2020; 13:108072.

10. Li B, Yang J, Zhao F, Zhi L, Wang X, Liu L. Prevalence and impact of cardiovascular metabolic diseases on COVID-19 in China. Clin. Res. Cardiol. 2020; 109(5):531-538.

11. Fadini GP, Moriori ML, Longato E, Avogaro A. Prevalence and impact of diabetes among people infected with SARS-CoV-2. J Endocrinol Investig. 2020;43(6):867-869.

12. Wang D, Hu B, Hu C, Zhu F, Liu X, Zhang J, Wang B, Xiang H, Cheng Z, Xiong Y, Zhao Y. Clinical characteristics of 138 hospitalized patients with 2019 novel coronavirus-infected pneumonia in Wuhan, China. J Ame Med Ass. 2020;323(11):1061-1069.

13. Klapka O, Slaby A. Visual Analysis of Search Results in Scopus Database. In International Conference on Theory and Practice of Digital Libraries 2018: 340-343.

14. Aria M, Cuccurullo C. bibliometric: An R-tool for comprehensive science mapping analysis. J Informer. 2017; 1;11(4):959975. 